\title{
THE RAE TABLE OF EARTH SATELLITES
}

1957-1986 


\title{
THE RAE TABLE OF EARTH SATELLITES
}

\author{
$1957-1986$ \\ compiled at
}

The Royal Aircraft Establishment, Farnborough, Hants, England

by

D.G. King-Hele, FRS, D.M.C. Walker, PhD, J.A. Pilkington, BSc, A.N. Winterbottom, H. Hiller, BSc and G.E. Perry, MBE

The Table is a chronological list of the 2869 launches of satellites and space vehicles between 1957 and the end of 1986, giving the name and international designation of each satellite and its associated rocket(s), with the date of launch, lifetime (actual or estimated), mass, shape, dimensions and at least one set of orbital parameters. Other fragments associated with a launch, and space vehicles that escape from the Earth's influence, are given without details. Including fragments, more than 17000 satellites appear in the 893 pages of the tabulation, and there is a full Index. 
C Crown copyright $1981,1983,1987$

Softcover reprint of the hardcover 3rd edition 1987 978-0-333-39275-1

Published by permission of the Controller of

Her Majesty's Stationery Office.

All rights reserved. No part of this publication may be reproduced, or transmitted, in any form or by any means, without permission.

Published in the United States and Canada by STOCKTON PRESS, 1987

15 East 26th Street, New York, N.Y. 10010

\section{Library of Congress Cataloging-in-Publication Data}

The R.A.E. table of earth satellites, 1957-1986.

Rev. ed. of: The RAE table of earth satellites, 19571980. 2nd ed. 1981.

1. Artificial satellites - Registers. I. King-Hele, Desmond G. II. Royal Aircraft Establishment (Great Britain) III. RAE Table of earth satellites, 1957-1982. IV. Title: RAE Table of earth satellites, 1957-1986. TL796.6. E2R253 1987 629.46’0216 87-10204

ISBN 978-0-935859-05-8

First published 1981, second edition 1983, third edition 1987 by MACMILLAN PUBLISHERS LTD (Journals Division)

Distributed by Globe Book Services Ltd

Canada Road, Byfleet, Surrey KT14 7JL, England

\section{British Library Cataloguing in Publication Data}

The RAE table of earths satellites 1956-1986.

-3 rd ed.

1. Artificial satellites - Tables

I. King-Hele, D.B. II. Royal Aircraft

Establishment III. The RAE table of earth

satellites, 1957-1986

629.47 TL796

ISSN 0265-3931

ISBN 978-1-349-07995-7 ISBN 978-1-349-07993-3 (eBook)

DOI 10.1007/978-1-349-07993-3 


\section{INTRODUCTION}

\section{HOW THE TABLE BEGAN AND GREW}

When the first satellite Sputnik 1 was launched on 4 October 1957, scientists at the Royal Aircraft Establishment, Farnborough, had already made several studies of Earth satellites and their orbits, stemming from work earlier in the 1950s on the ballistic missile Blue Streak and the Skylark research rocket. Wi.thin a few days of its launching, Sputnik 1 was being regularly tracked by a radio interferometer constructed at the RAE's outstation at Lasham, Hampshire. The satellite's orbit was determined from these observations, and the observed decay rate was used to evaluate upper-atmosphere density. The work was described in an article published in Nature on 9 November 1957 (Volume 180, pages 937-941).

On 3 November 1957, Sputnik 2 was launched, and the need for a regular prediction service was recognized. Initially the service was provided by the Royal Greenwich Observatory, Herstmonceux, and was taken over by the RAE in January 1958. The first US satellite Explorer 1 was launched on 1 February 1958, to be followed by Vanguard 1 and Explorer 3 during March, and Sputnik 3 in May. Soon there were numerous requests for a list of satellites, and Doreen Walker, who was responsible for providing the predictions, compiled the first RAE Table of satellites - a single sheet - in July 1958. From these small beginnings the Table has 'just growed', the original format being retained almost unchanged, apart from conversion to metric units. Very few copies of this 'first edition' still exist, so a facsimile of the original sheet, slightly reduced in size, is printed on page ii.

From the beginning it was apparent that there would be little information available on the sizes, shapes and masses of the many Russian rockets in orbit, and the decision was taken to make rough estimates of the size and shape from visual observations, and then to deduce the mass from the observed orbital decay rate and the (by then) known upper-atmosphere density. This policy has been pursued ever since, and the estimates have been improved over the years as more information became available.

Since 1957 the RAE has specialized in the analysis of satellite orbits to determine upper-atmosphere density and winds, and the Earth's gravitational field. 


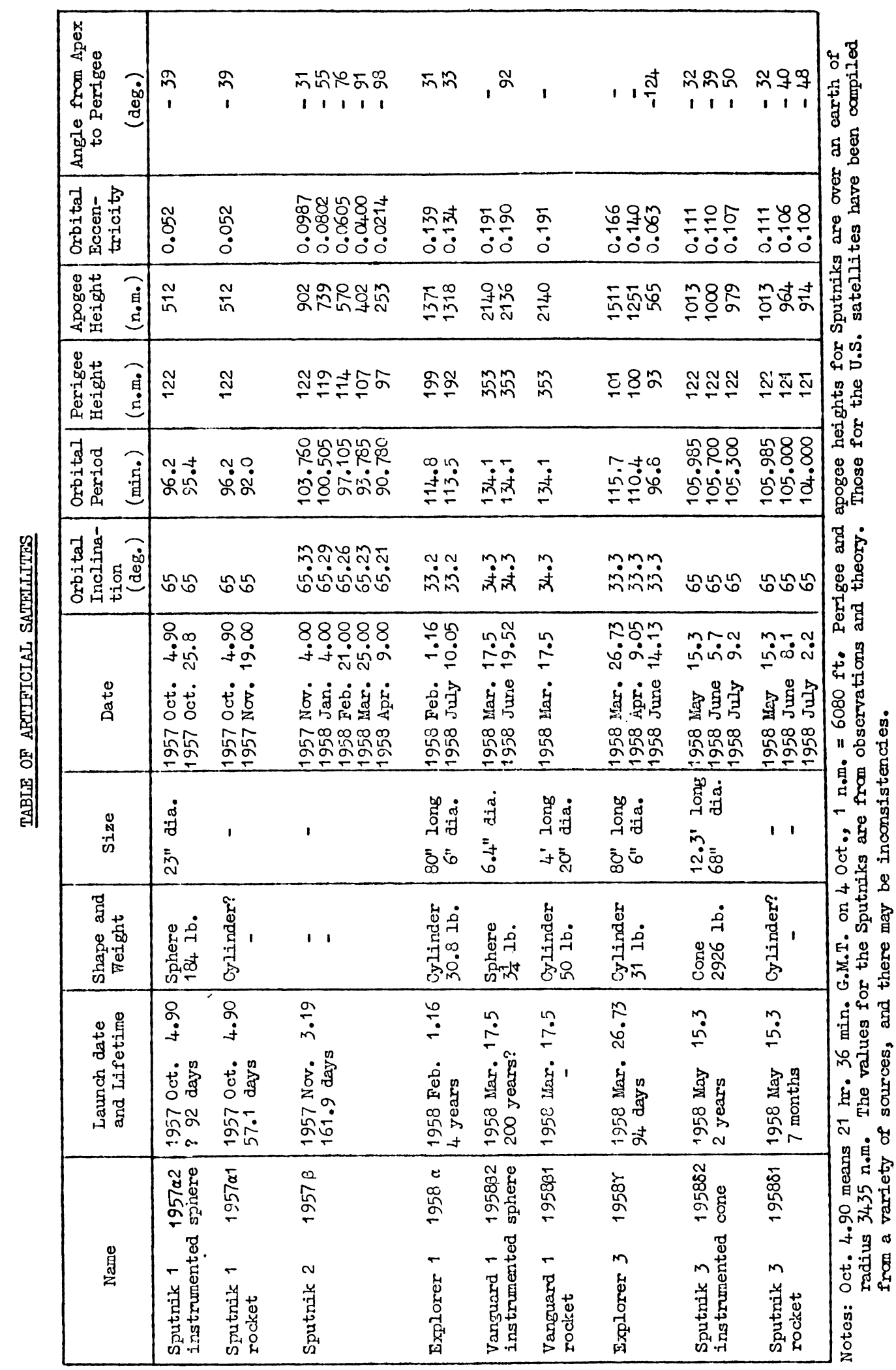


This work depends on choosing satellites for observation, determining the orbits from the observations, and then analysing the orbits. In order to choose suitable satellites, a listing like that in the Table is needed, including reasonably accurate estimates of the satellite lifetimes. These lifetime estimates are vital, because it is no good selecting a satellite for long-term studies of the gravitational field, only to find that it decays within two years. Conversely, it is no good selecting a satellite for studies of atmospheric winds if no useful results can be obtained for thirty years or more.

The estimation of lifetime has proved to be the most creative and difficult aspect of the Table. The orbits of most satellites are appreciably affected by the drag of the upper atmosphere, which makes the orbit contract and eventually brings the satellite to a fiery end in a plunge into the lower atmosphere. The lifetime is controlled by the upper-atmosphere density: if the density doubles, the lifetime will be halved. In fact, the density at a height of $500 \mathrm{~km}$ can be more than ten times greater at the maximum of the eleven-year sunspot cycle than at the minimum; and predictions of the intensity and timing of future sunspot maxima are notoriously unreliable. So it is very difficult to make good estimates for lifetimes greater than 5 years. Cr a shorter timescale, problems arise from the day-to-night variation in density, by a factor of up to 6 ; from the semi-annual variation, by a factor of up to 3 ; and from irregular day-to-day variations. Also there are some satellites in highly eccentric orbits for which the lifetime is governed by the gravitational attraction of the Sun and Moon; lengthy computations are then needed, extending over the life of the satellite, perhaps 10 or 20 years. Balloon satellites form another unusual group, with their lifetime controlled by the radiation pressure of sunlight.

Though the need for the Table of satellites arose from the work on orbit analysis, the Table was so appreciatively received, not only by individuals but also in official US and USSR publications, that we decided to continue sending it to qualified recipients. By 1980, however, the printing and distribution had become expensive and burdensome, and the choice of recipients had become difficult. So RAE welcomed the offer of Macmillan Press to publish the Table. The first edition, published in 1981, covered the years 1957-1980; the second edition, published in 1983, covered the years 1957-1982. Now a third edition is called for, covering the first 30 years of launchings, 1957-1986.

As before, the Table has been printed from the original masters, rather than being completely reset in type. However, many thousands of amendments have been made to the original pages and some pages have been retyped. This method 
suffers some slight inelegance from mismatching of type-faces no longer available, but has the great advantages of quicker production and better accuracy.

The present volume is fully updated to the end of 1986; it supersedes all previous issues and will serve as the master copy for future amendment.

The Table has grown to its present size only after much hard work, and the contributions of the compilers and others to the work over the years have been as follows. Desmond King-Hele has had general responsibility continuously from the outset. The detailed work was done by Doreen Walker between 1958 and 1961, and from then until 1968 mainly by Janice Rees, Alan Pilkington and Eileen Quinn. Since 1968 the Table has been issued monthly: the task of organizing data on the increasing traffic in space and identifying new launches was done by the late Harry Hiller from 1968 to 1980 and by Alan Winterbottom thereafter. With the aid of this information, the draft of each monthly issue was produced by Alan Pilkington from 1968 to 1984, and by Geoffrey Perry for 1985 and 1986. Doreen Walker has been responsible for the lifetime predictions, and has also undertaken the exacting editorial and organizational work of updating and preparing the volumes for publication.

\section{THE NUMBER OF LAUNCHES}

In 1957 there were two satellite launches, by the USSR; in 1958 there were eight, of which seven were by the USA and one by the USSR. From then until 1967 the total numbers of launchings of satellites and space vehicles increased every year except 1963, and the yearly total for 1967 was 127 launches. During the next twenty years the world changed greatly, and most activities either strongly increased or seriously declined; but the annual numbers of space launchings changed surprisingly little. The maximum annual number of launches between 1965 and 1986 was 129 in 1984 and the minimum was 103 in 1986. The average number of launches annually in the years 1965-1986 was 117 (ignoring decimals of a launch, which are difficult to visualize). The total number of launches for 1957-1986 was 2869 .

The diagram opposite shows the yearly numbers of launches of satellites and space vehicles in histogram form, with division into launches by the USSR (dark stippling), the USA (light stippling) and 'others' (large dots). The 'others' include launches by other countries and 'joint' launches, for example launches by the USA for international organizations like Intelsat, or by the USSR for the Intercosmos consortium. The European launches with the Ariane rocket are also counted among the 'others'. 


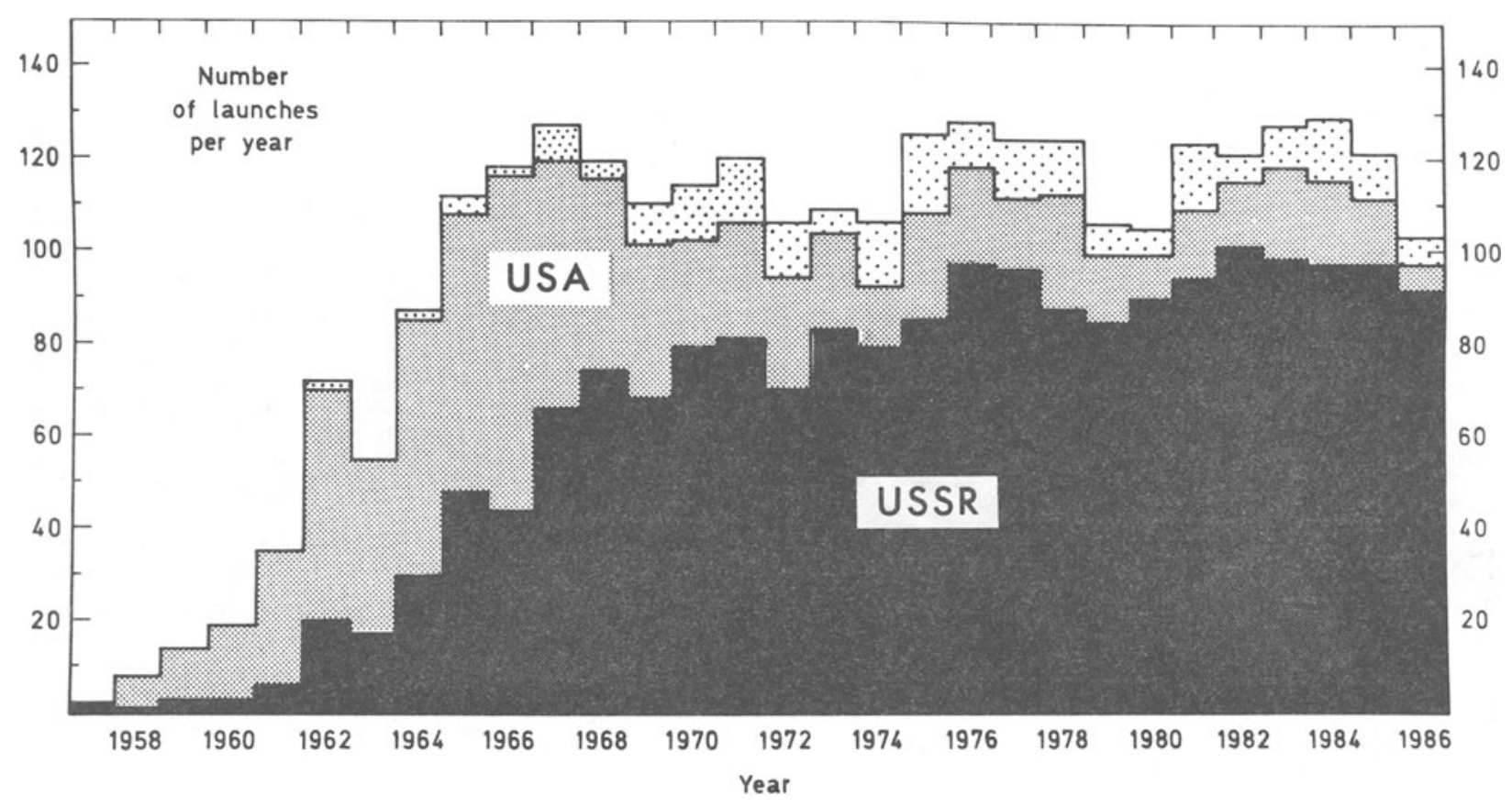

The diagram shows that the USA had more launches than the USSR in each year between 1958 and 1966, but the situation reversed in 1967. During the 1970s the preponderance of USSR launches continued, and increased; in the years 1980-1986 the proportions were: $80 \%$ USSR; $12 \%$ USA; and $8 \%$ others.

After the USSR and USA, the next country to launch a satellite with a home-made rocket was France in 1965. Five years later, Japan became the fourth space-launching country, soon followed by China (1970) and the UK (1971). There was then another long interval before the appearance of the seventh country, India, in 1980 .

The 2869 launches are tabulated year by year in 29 categories in the table on page vi. The first 7 categories are national launches. Then come 22 'joint' categories, with the launching country first. One of these, USA/Shuttle (24 launches) is treated as ' $\mathrm{USA}^{\prime}$ in the diagram above. The rest are treated as 'others' in the diagram, and include USA/Intelsat (34 launches), USSR/Intercosmos (23) and Europe/Ariane (14). 
vi

\begin{tabular}{|c|c|c|c|c|c|c|c|c|c|c|c|c|c|c|c|c|c|c|c|c|c|c|c|c|c|c|c|c|}
\hline 樆 & & 号 & $\therefore$ & & & & & $\stackrel{d}{d}$ & & & & & & & & & & & & & & $v-$ & & & & & -1 & : \\
\hline 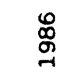 & & $n \sim$ & & ' & 1 & 1 & 1 & - & & & 1 & 1 & ' & ' & ' & ' & ' & ' & ' & ' & & 11 & & 1 & ' & 1 & 1 & $\stackrel{\infty}{0}$ \\
\hline$\stackrel{\mathscr{m}}{\stackrel{\mathscr{g}}{\sim}}$ & & $\hat{\sigma}$ & -1 & 1 & 1 & 1 & $m$ & $\sigma$ & -1 & & 11 & 1 & 1 & 1 & 1 & 1 & ' & 1 & ' & ' & ' & 1 & & 1 & ' & 1 & 1 & $\underset{\exists}{\exists}$ \\
\hline 丞 & & $\delta \stackrel{m}{\sim}$ & 0 & 1 & 1 & 1 & -1 & $n$ & 1 & & $1-$ & $\begin{array}{r}-1 \\
-1\end{array}$ & $1-$ & 1 & ' & ' & ' & ' & ' & 1 & & 1 & & ' & ' & 1 & -1 & $\underset{్}{\text { త్ }}$ \\
\hline 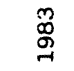 & & $\infty \stackrel{\infty}{\infty}$ & $r$ & 1 & -1 & 1 & -1 & $\nabla$ & 1 & & & 1 & 1 & 1 & 1 & 1 & I & 1 & ' & 1 & ' & 1 & & & 1 & -1 & 1 & $\hat{\exists}$ \\
\hline 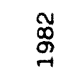 & & $\delta \Rightarrow$ & 4 & 1 & 1 & 1 & $\sim$ & $m$ & 1 & & 11 & 17 & 4 & 1 & 1 & ' & ' & 1 & ' & ' & ' & 1 & & & -1 & 1 & 1 & $\mathbb{J}$ \\
\hline$\stackrel{\vec{D}}{\stackrel{\sim}{\sim}}$ & & 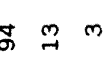 & - & 1 & $r$ & 1 & $\sim$ & $\sim$ & $\sim$ & & $1-1$ & -1 & 1 & -1 & 1 & 1 & ' & -1 & ' & ' & 1 & 1 & & 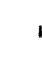 & ' & 1 & 1 & 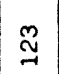 \\
\hline 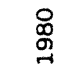 & & $\infty \approx N$ & 1 & 1 & -1 & 1 & $\rightarrow$ & 1 & 1 & & 11 & 11 & 1 & 1 & 1 & ' & 1 & 1 & ' & 1 & 1 & 1 & & ' & 1 & 1 & 1 & $\stackrel{n}{\circ}$ \\
\hline 古 & & $\Phi 乞$ & 1 & 1 & 1 & 1 & 1 & 1 & $\sim$ & & $1-1$ & $\begin{array}{r}-1 \\
\end{array}$ & 1 & ' & 1 & ' & 1 & -1 & ' & 1 & 1 & 1 & & 1 & 1 & 1 & 1 & $\stackrel{-}{\circ}$ \\
\hline$\stackrel{\infty}{S}$ & & $\stackrel{\infty}{\sim}$ & $\rightarrow$ & 1 & 1 & 1 & $N$ & 1 & - & & $N \quad 1$ & $1-$ & $4-1$ & 1 & & ' & ' & & - & 1 & 1 & 1 & & 1 & I & 1 & 1 & $\stackrel{\mathbb{Z}}{\sim}$ \\
\hline$\stackrel{5}{\sigma}$ & & ه & 1 & 1 & 1 & 1 & - & 1 & -1 & & m 1 & 1 & -1 & 1 & -1 & 1 & ' & & $\sim$ & ' & - & 4 & & & I & 1 & 1 & $\underset{\sim}{\mathbb{N}}$ \\
\hline$\stackrel{\circ}{\stackrel{్}{్}}$ & & $\delta \vec{~}$ & ${ }^{4} N$ & 1 & 1 & 1 & -1 & 1 & $\sim$ & & 11 & $1-1$ & 4 & 1 & & -1 & 1 & & ' & & - & 4 & & & ' & 1 & ' & 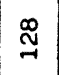 \\
\hline$\stackrel{\text { مै }}{\sigma}$ & & $\stackrel{\infty}{\infty} \sim$ & $m$ & $m$ & 1 & 1 & N & 1 & $\sim$ & & $\rightarrow 1$ & $1-1$ & & -1 & 1 & ' & - & 1 & ' & & ' & 1 & & & 1 & 1 & 1 & $\stackrel{\mathscr{N}}{N}$ \\
\hline ฐั & & 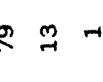 & 4 & 1 & 1 & 1 & - & 1 & $\sim$ & & 10 & $\rightarrow \quad 1$ & 1 & ' & -1 & N & - & 1 & ' & & ' & 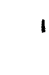 & & & 1 & 1 & 1 & $\stackrel{-}{\circ}$ \\
\hline 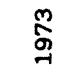 & & $\infty \quad \vec{\sim} \quad$ & 1 & 1 & 1 & 1 & -1 & 1 & $\sim$ & & 11 & $1-$ & 4 & - & 1 & I & ' & ' & ' & ' & ' & 1 & & & 1 & 1 & 1 & 임 \\
\hline స్ & & $R \Phi$ & .1 & 1 & 1 & 1 & N & 1 & m & & $\infty 1$ & $1-$ & 4 & -1 & 1 & -1 & 1 & ' & ' & ' & ' & 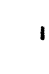 & & & 1 & 1 & 1 & ‡ \\
\hline 험 & & to $\stackrel{\sim}{\sim} \sim$ & $\rightarrow$ & - & 1 & -1 & N & 1 & -1 & & $1-1$ & $-1-1$ & $4-1$ & -1 & -1 & ' & - & 1 & ' & ' & ' & ' & 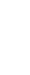 & & ' & 1 & 1 & $\stackrel{ }{~}$ \\
\hline 옴 & & $\mathbb{N}-$ & -1 & -1 & 1 & 1 & $m$ & 1 & $\sim$ & & 17 & -1 & - & 1 & 1 & ' & ' & 1 & I & - & 1 & 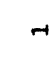 & ( & 1 & 1 & 1 & 1 & $\Xi$ \\
\hline$\stackrel{\circ}{\circ}$ & & 80 & & 1 & 1 & 1 & $m$ & 1 & $\sim$ & & $-1-1$ & $-1-1$ & 4 & ' & I & -1 & 1 & ' & ' & ' & ' & 1 & t & 1 & 1 & 1 & 1 & 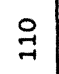 \\
\hline 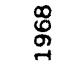 & & $\forall \neq 1$ & & 1 & 1 & 1 & $\rightarrow$ & 1 & 1 & & m 1 & 11 & 1 & ' & 1 & ' & ' & ' & I & ' & ' & . & & ' & 1 & 1 & 1 & $\stackrel{\approx}{\exists}$ \\
\hline$\stackrel{\circ}{\circ}$ & 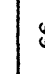 & : & 1 & $\sim$ & 1 & 1 & $m$ & 1 & 1 & & $1-1$ & $r \quad 1$ & 1 & ' & -1 & ' & ' & ' & ' & - & 1 & 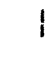 & & ' & ' & 1 & ' & $\hat{\Xi}$ \\
\hline 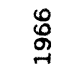 & & $g \approx 1$ & & $r$ & 1 & 1 & -1 & 1 & 1 & & 11 & 1 & 1 & ' & 1 & ' & ' & ' & ' & ' & ' & & & ' & I & ' & 1 & $\stackrel{\infty}{\exists}$ \\
\hline 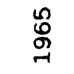 & & 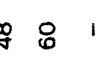 & & -1 & 1 & 1 & -1 & 1 & 1 & ' & 11 & $1-1$ & 4 & ' & ' & ' & - & 1 & ' & ' & ' & 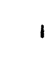 & & & 1 & 1 & 1 & $\cong$ \\
\hline ఫ্ & & 品品 & & 1 & 1 & 1 & i & 1 & 1 & & $1-1$ & -1 & 1 & & $\rightarrow$ & 1 & ' & 1 & ' & ' & ' & & & & 1 & 1 & 1 & $\hat{\infty}$ \\
\hline$\stackrel{\mathscr{8}}{\stackrel{్}{\circ}}$ & & $\hat{~}{ }_{\infty}^{\infty} \quad 1$ & & 1 & 1 & 1 & 1 & 1 & 1 & & 11 & 1 & & & 1 & ' & ' & 1 & ' & ' & & & & & 1 & 1 & 1 & 吕 \\
\hline$\stackrel{\widetilde{్}}{\stackrel{్}{్}}$ & & N & 1 & 1 & 1 & 1 & 1 & 1 & 1 & 1 & $1-1$ & $-1-$ & & & 1 & I & 1 & 1 & ' & I & ' & I & & & 1 & 1 & 1 & $\cong$ \\
\hline$\stackrel{\vec{\circ}}{\stackrel{్}{\prime}}$ & & 0 o 1 & 1 & 1 & 1 & 1 & 1 & 1 & 1 & & 11 & 11 & 1 & & 1 & I & ' & ' & ' & ' & ' & 1 & & I & 1 & 1 & & 足 \\
\hline$\stackrel{\circ}{\stackrel{\leftrightarrow}{\circ}}$ & & $n \stackrel{0}{n} \quad 1$ & 1 & 1 & 1 & 1 & 1 & 1 & 1 & & 11 & 11 & & & & & ' & 1 & ' & ' & 1 & 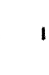 & & ' & 1 & 1 & 1 & $\stackrel{9}{7}$ \\
\hline 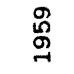 & & $m=1$ & ' & 1 & 1 & 1 & 1 & 1 & 1 & & 11 & 11 & & & & & ' & 1 & & & & 1 & & 1 & 1 & 1 & 1 & $\Xi$ \\
\hline 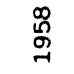 & & -1 & & 1 & 1 & 1 & 1 & 1 & 1 & & 11 & 11 & & & & & & & & & & & & & & 1 & 1 & $\infty$ \\
\hline 总 & c & $\begin{array}{llll} & 1 & 1\end{array}$ & ' & 1 & 1 & 1 & 1 & 1 & 1 & & 11 & 1 & 1 & 1 & 1 & ' & ' & & & & & & & & 1 & 1 & 1 & $\sim$ \\
\hline & & 蒡芯 & & & & & & 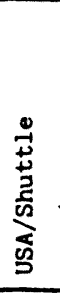 & & & 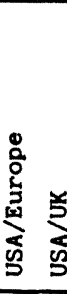 & 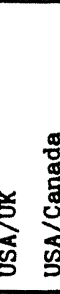 & & & & & & & 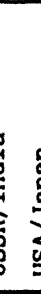 & 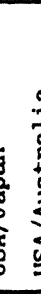 & 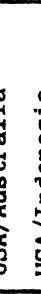 & & & & 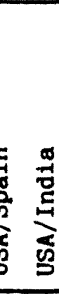 & 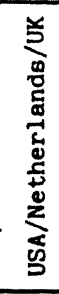 & 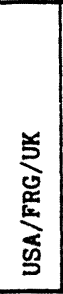 & 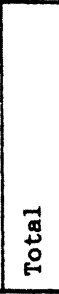 \\
\hline
\end{tabular}




\section{THE PURPOSE OF THE LAUNCHINGS}

Launching a satellite is an expensive exercise, and, on the assumption that human affairs still retain some relics of rationality, it is reasonable to ask what was the purpose of the launchings. The difficult task of assigning the launches to particular categories was undertaken by $\operatorname{Dr}$ Charles Sheldon (in "United States and Soviet Progress in Space", US Congressional Research Service Report 81-27, 1981). The figures following are based on his findings.

He divides the launches into two main groups, military and civil. About $60 \%$ of the launchings have been primarily military, the proportion being greater for the USSR than for the USA. In this military group, more than half have been photographic-reconnaissance satellites, about $10 \%$ have been for communications, rather less than $10 \%$ for navigation, and the remainder for a variety of purposes, such as early warning of missile attack, ocean surveillance, electronic '1istening in', and tests of satellite interception.

In the civil group of launchings, about $40 \%$ have had scientific research as their aim: most of these satellites were designed to examine the Earth and its environment; other targets for research have been the planets, the Sun, the Moon or the stars. Nearly $20 \%$ of the civil group have been communications satellites, more than $10 \%$ weather satellites, and rather less than $10 \%$ manned satellites. Among the others have been many development satellites, for testing new instruments or engineering techniques, and a few satellites for the mapping of Earth resources.

\section{NAMES AND DESIGNATIONS}

Each launching organization likes to give each of its satellites a 'pet name' to be used by those working with the data from it. Many of these national names are familiar - Apollo, Ariel, Cosmos, Skylab, and so on - but some are weird acronyms like Spades (Solar Perturbation of Atmospheric Density Experiments Satellite); sometimes two agencies use the same name (Geos is an example); and some satellites remain nameless.

To bring all space launches into a single system, the International Committee on Space Research (known as COSPAR) has given all satellites and fragments an international designation based on the year of launch and the number of successful launches during the year. Thus the British satellite Prospero is designated 
1971-93A, because it was launch 93 of the year 1971. Usually the letter A is given to the instrumented spacecraft, $B$ is given to the rocket and C, D, E, .. to fragments, the letters $I$ and $O$ being omitted. Thus 1971-93B is the rocket that accompanied Prospero into orbit and 1971-93C is a fragment - an aerial that was knocked off during injection into orbit. If several spacecraft are sent into orbit in one launch, they are usually given the letters, A, B, C, ... thus in the many eight-satellite launches by the USSR, the satellites are designated $\mathrm{A}-\mathrm{H}$ and the rocket is $\mathrm{J}$. When there are more than 24 pieces from one launch, as can happen after an explosion, the sequence continues after $Z$ with $A A, A B$, $\mathrm{AC}, \ldots \mathrm{AZ}$, and then $\mathrm{BA}, \mathrm{BB}, \mathrm{BC}, \ldots \mathrm{BZ}$, and so on. The greatest number of fragments so far catalogued from one launch is 466, resulting from the explosion of the satellite 1965-82A.

Besides reducing confusion, the international designation is useful because it gives not only the year but also the approximate month of 1 aunch. Since 1965 there have been approximately 10 launches per month, so the month of launch can be approximately estimated from the designation. Thus Prospero (1971-93A) would be assigned to approximately the 10 th month of 1971, and it was in fact 1 aunched on 28 0ctober 1971. Obviously there may be an error of one or two months because of the variation in the annual numbers of launches.

In the years 1957-1962 a different system was used, in terms of the 24 Greek letters. Thus the first launch of 1960 was 1960 alpha $(1960 \alpha)$, the second 1960 beta $(1960$ B), and so on. After 24 launches, double letters were used with $\alpha \alpha, \alpha \beta, \ldots$ for 1 aunches $25,26, \ldots$. The names of the Greek letters are listed on page xvi.

In the Table (pages 1-893) the national names are given first, followed by the international designations. The listing is chronological.

The index (pages 894-935) gives the national names, listed alphabetically, with the corresponding international designations and the appropriate page numbers. The full names of all satellites known by acronyms also appear in the index.

\section{SATELLITE ORBITS}

Readers who are unfamiliar with orbits may welcome an explanation of the terms used on each page of the Table to specify the size, shape and orientation of the orbits. 
A satellite succeeds in entering orbit if its launching rocket can take it above the dense atmosphere and propel it nearly horizontally at a high enough speed. If the orbit is near-circular, $150 \mathrm{~km}$ may be regarded as the minimum height for avoiding rapid attrition of the orbit by air drag, and at this height the minimum velocity for attaining orbit is $7.8 \mathrm{~km}$ per second. If the launcher

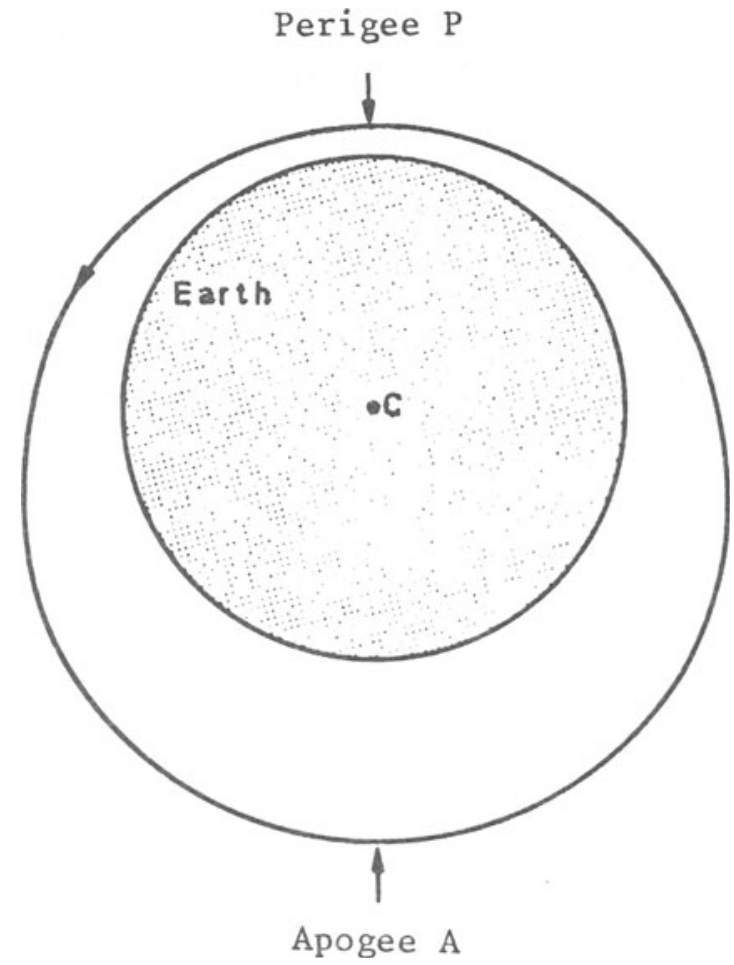

injects the satellite into orbit horizontally (at a high enough speed), the satellite will fly out to a greater height at the opposite side of the Earth, and will enter an elliptic orbit, as shown in the diagram. The point $P$ on the ellipse where the sate1lite comes closest to the Earth is called the perigee and the point of maximum height is the apogee, A. The height of a sate1lite's orbit is specified by its average distance from the Earth's centre, that is, half the sum of the apogee and peri-

gee distances. This average distance, usually denoted by the symbol $a$, is called the semi major axis, the major axis being the distance AP between apogee and perigee, the longer diameter of the ellipse. For a circular orbit the semi major axis is of course the radius of the orbit.

The distance of perigee and apogee from the Earth's centre are not very useful quantities to tabulate: what we need to know is the height of perigee and apogee above the Earth's surface, and the Table gives perigee and apogee heights above a spherical Earth of radius $6378 \mathrm{~km}$ (the equatorial radius). In practice both the perigee distance and the Earth's radius vary with latitude, so the simple definition above is not exact, but it usually gives heights within $20 \mathrm{~km}$ of the instantaneous perigee and apogee heights and therefore provides a good general guide to the height of a satellite at perigee and apogee.

The shape of a satellite orbit is specified by its eccentricity, defined as the apoget height minus the perigee height, divided by the major axis. 'lhus a 
satellite with semi major axis $7500 \mathrm{~km}$, perigee height $300 \mathrm{~km}$ and apogee height $1944 \mathrm{~km}$, would have an eccentricity of $1644 / 15000=0.110$. If the orbit is circular, the perigee and apogee heights are equal, and the eccentricity is zero. In practice, nearly circular orbits are convenient for many purposes, and a large proportion of actual orbits will be found to have eccentricities less than 0.01 .

The major axis of a satellite's orbit also decides its orbital period, the time it takes to go once round the Earth. The orbital period can be as low as 88 minutes if the average height is $200 \mathrm{~km}$; the orbital period is about 90 minutes when the average height is $300 \mathrm{~km}$; it is about 92 minutes when the height is $400 \mathrm{~km}$; and so on, with periods of 100 and 120 minutes corresponding to average heights of about $800 \mathrm{~km}$ and $1700 \mathrm{~km}$ respectively. If we go out further, an orbital period of 12 hours occurs when the average height is $20000 \mathrm{~km}$; and the period is 24 hours when the average height is $36000 \mathrm{~km}$. Since the Earth rotates once, relative to the stars, every 23 hours 56 minutes (1436 minutes), a satellite in an eastbound equatorial orbit with a period of 1436 minutes keeps pace with the Earth's rotation and appears stationary as seen from the Earth. This is the synchronous orbit much favoured for communication satellites, and many nearsynchronous orbits will be found in the Table.

There are several possible definitions of orbital period, and that used in the Table is the nodal period, defined as the time between successive northward crossings of the Earth's equator by the satellite. (Another possible definition, not used here, is the time from one perigee to the next, the anomalistic period.)

As well as the size and shape of an orbit, we need to know whether it goes over the poles or stays near the equator. This is specified by the inclination of the orbit to the equator, that is, the angle $i$ between the orbital plane and the plane of the Earth's equator as shown in the diagram opposite, where the track is assumed to be over a spherical 'Earth'. The point $N$, where the orbit crosses the equator going north, is called the ascending node, whence the name 'nodal period' previously defined.

The orbital inclination, given for each satellite in the Table, tells us the maximum latitude attained by a satellite as it travels round the world: the maximum latitude is equal to the orbital inclination, if we ignore small perturbations. Thus an inclination of $90^{\circ}$ implies an orbit passing directly over the north and south poles on each revolution; an orbit of inclination $50^{\circ}$ passes 


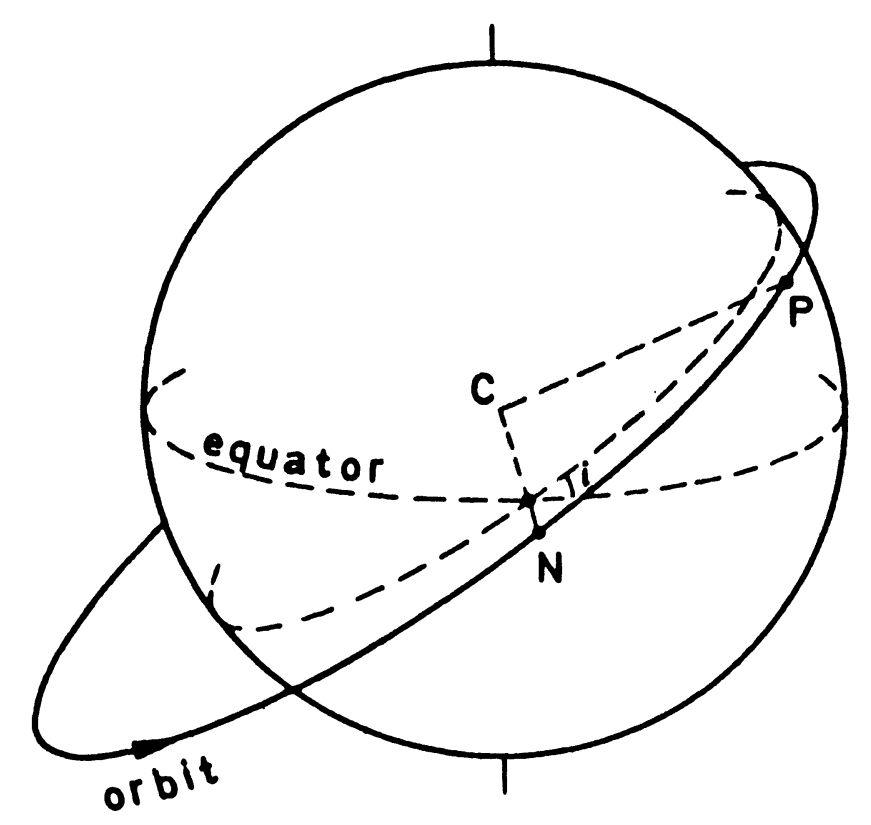

over all latitudes between $50^{\circ} \mathrm{N}$ and $50^{\circ} \mathrm{S}$; while an orbit of inclination $10^{\circ}$ is confined to latitudes less than $10^{\circ}$.

The next orbital parameter is the argument of perigee, which specifies the position of the perigee $P$ relative to the equatorial plane. The argument of perigee is defined as the angular distance round the orbit between the ascending node $\mathrm{N}$ and the perigee $\mathrm{P}$, and it is given by the angle $N \hat{C P}$ in the diagram, where $C$ is the Earth's centre. The

interpretation of the argument of perigee is fairly obvious from the diagram, but is listed below for reference.

\begin{tabular}{|c|l|}
\hline Argument of perigee & Corresponding geographical position of perigee \\
\hline $0^{\circ}$ & At equator going north (N in the diagram) \\
In northern hemisphere with satellite going north \\
$0^{\circ}-90^{\circ}$ \\
$90^{\circ}$ \\
$90^{\circ}-180^{\circ}$
\end{tabular} $\begin{aligned} & \text { At maximum latitude north } \\
& 180^{\circ} \\
& 180^{\circ}-270^{\circ}\end{aligned}$

One further orbital parameter, not given in the Table, is the lungitude of the node; this is of less significance, though orbital specialists would have welcomed its inclusion. 
xii

\section{GUIDE TO THE TABLE}

The data given in the main Table, for all satellites other than fragments, are as follows.

Column 1 gives the name of the satellite and its international designation. If the name is unknown, the launching vehicle is indicated in square brackets. Doubtful entries are distinguished by question marks . Letters to the left of Column 1 have the following meanings:

B denotes unmanned satellites which carried live biological specimens.

$D$ denotes satellites no longer in orbit on 1 January 1987. (For fragments, $\mathrm{D}$ indicates that a11 have decayed; $1 \mathrm{~d}$ indicates that one has decayed; $2 \mathrm{~d}$ indicates that two have decayed, and so on.)

L denotes satellites with retroreflectors for laser tracking.

$M$ denotes manned satellites; $2 M$ indicates a crew of two at launch; etc.

$\mathrm{p}$ indicates that pieces were picked up on Earth after re-entry.

$R$ denotes satellites which returned to Earth and were recovered intact. $r$ denotes satellites carrying capsules which were successfully recovered.

$\mathrm{T}$ denotes satellites still transmitting radio signals on 1 January 1987.

Column 2 gives the launch date, lifetime (actual or estimated), and descent date (if appropriate). The dates are given in days and decimals of a day UT. Thus 1979 May 18.70 means "16h 48m UT (or GMT) on 18 May 1979". Actual lifetimes are given in days (and decimals of a day, if known). Estimated lifetimes are given in years, with decimals or fractions of a year as appropriate. Manoeuvrable satellites still in orbit on 1 January 1987 have 'manoeuvrable' in place of an estimated lifetime.

Column 3 gives the basic shape of the satellite and its mass in kilograms $(1 \mathrm{~kg}=2.205 \mathrm{lb})$. Sometimes the shape defies description in a few words and the description given is only approximate.

Column 4 gives the basic dimensions of the satellite in metres. Aerials, paddles carrying solar cells, and other components projecting from the main body are not normally taken into account when giving the size and shape $(1 \mathrm{~m}=3.281 \mathrm{ft})$.

Column 5 gives the date for the orbital information in Columns 6-12. Column 6 gives the inclination of the orbit to the equator, in degrees. 
Column 7 gives the nodal period of revolution - the time interval, in minutes, between successive northward equatorial crossings by the satellite.

Columns 8-11 specify the size and shape of the orbit. The quantities tabulated are the semi major axis $a$, in kilometres; the eccentricity $e$; and the perigee and apogee heights, $\{a(1-e)-R\}$ and $\{a(1+e)-R\}$ respectively, where $R$ is the Earth's equatorial radius, $6378.1 \mathrm{~km}$. $(1 \mathrm{~km}=0.6214$ statute miles $=3281 \mathrm{ft}=0.5396$ nautical miles. $)$

Column 12 gives the argument of perigee - the angle, measured round the orbit, from the northward equatorial crossing to the perigee.

The names of space vehicles (which have escaped from the dominance of the Earth's gravitational field) are given below the table, on the appropriate pages.

The index (pages 894-935) gives the names of the satellites in alphabetical order, with the international designation of each and the page on which details may be found. Satellites which are not Russian or American may be found in the index by referring to the appropriate country.

\section{METHODS USED TO COMPILE THE TABLE}

Our chief difficulty has been the lack of accurate information about the size, shape and weight of most of the satellites. The majority of launchings are military, and little information is released about these satellites or their final-stage rockets; we have to rely largely on deductions from their visual appearance in the night sky and on identifying previous launches of similar character. In contrast, we have full details of most international satellites and those launched by the US National Aeronautics and Space Administration (NASA).

\section{Names and designations of satellites}

The names given by the launching authorities are indicated when known. For unnamed United States Air Force satellites, the launch vehicle is given in square brackets: the lists issued by the United Nations have been useful in identifying the launch vehicles and orbits for these satellites.

When a name is abbreviated to initials only, the meaning of the acronym is given as a footnote for the first satellite of that name. The full names are included in the index.

The international designation of each satellite launching is allocated by the World Warning Agency on behalf of COSPAR. But the identification of particular components in a multiple launch has often depended on visual observations, 
xiv

since an experienced visual observer can usually distinguish between a satellite and $i$ ts rocket, and may be able to recognize the species of rocket or satellite being observed. Inevitably, however, there is a possibility of confusion in identifying components in a multiple launch.

The techniques of visual observing are described in Observing Earth Satellites by D. King-Hele (Macmillan London, 1983).

'Fragments' may be defined loosely as 'non-functional components', or, more precisely, as any components left over after accounting for the instrumented satellite, the various rocket stages and any other major mechanical component (such as Molniya 'launchers'). Fragments thus include cast-off heat shields, despin weights and inter-stage structures, as well as debris from explosions - the most prolific source of fragments.

\section{Lifetimes}

The orbits of most satellites contract slowly under the action of air drag, and the severity of the drag determines their lifetimes, which can be estimated from the orbital decay rates (unless the satellites are later swept up as space rubbish, or suffer other major perturbations). The decay rate depends on air density, and the density depends critically on solar activity, which cannot be accurately predicted. So most lifetime estimates are likely to be in error by $10 \%$ or more, and lifetime estimates of over 5 years may have much greater errors: if solar activity in future cycles should decline to the low levels prevalent in the late 17 th century, lifetimes of $20-50$ years given here would be seriously underestimated.

For most satellites in high-eccentricity orbits, such as the Molniya satellites and rockets, the lifetimes depend primarily on lunisolar perturbations rather than air drag, and have been estimated by numerical integration.

Methods for predicting lifetime are described in ESA SP-246, pages 29-37 (1986) and, in more detail, in RAE Technical Report 87030 (1987). The underlying theory is given in Satellite Orbits in an Atmosphere by D. King-Hele (Blackie, 1987).

\section{Weights and dimensions}

The weights and dimensions of the satellites come from Spacewarn launch telegrams, NASA Press Releases, and press and radio reports. Some indication of the accuracy is given by the number of significant figures. Often it is difficult to define the 'length' or 'diameter' when components of irregular size and shape are joined together, and dimensions are therefore sometimes approximate. 
For satellites of unknown mass and size, the average cross-sectional area $S$ can be approximately determined from the average brightness when observed visually; the mass/area ratio $\mathrm{m} / \mathrm{s}$ can be obtained from the rate of change of orbital period and the known air density at heights near perigee, to give a value for the mass $m$. Many of our values for the dimensions of Russian rockets rely on the detailed studies by Dr Charles Sheldon, in Soviet Space Programs 1971-75 (US Government Printing Office, Washington, 1976).

We hope that most of the weights and dimensions given with question marks are accurate to within a factor of 1.5 , ie that the real values are between $2 / 3$ and $3 / 2$ times the value given. It seemed better to give some indication of the weights and sizes, even if approximate, rather than to leave blanks.

\section{Orbital accuracy}

Orbital information has come from many sources. Most of the orbits are based on the elements issued by the North American Air Defense Command (NORAD), and the remainder come mainly from NASA and RAE orbits.

The accuracy of the orbits varies greatly between one satellite and another, and no detailed guide can be given. Most orbits, however, are believed to have an error (sd) of about $0.02^{\circ}$ in orbital inclination, $0.02 \mathrm{~min}$ in period, $2 \mathrm{~km}$ in semi major axis, $5 \mathrm{~km}$ in perigee and apogee heights (when the apogee height is less than $2000 \mathrm{~km}), 0.001$ in eccentricity $\mathrm{e}$, and perhaps $3^{\circ}$ in argument of perigee (if $\epsilon>0.02$ ). Some orbits are much more accurate than this, and some, particularly those with eccentricity exceeding 0.3 or with very short lifetimes, may be much less accurate.

\section{Radio transmissions}

A satellite is given the symbol $\mathrm{T}$ if it transmits radio signals during its first days in orbit. The cessation of radio signals is rarely publicized, so the removal of the $T$ is often based on the estimate that the average active life for radio transmission is about $2 \frac{1}{2}$ years for Soviet satellites and 7 to 8 years for US satellites. The most complete list of radio frequencies of satellites is in Telecommunication Joumal, Volume 44, No.2 (1977), updated in subsequent month1y issues of Telecomminication Joumal.

Locations of geosynchronous satellites are not given, because they are subject to drift. Current locations are available in a list issued regularly by NASA Goddard Space Flight Center. 
xvi

\section{LAUNCH SITES}

Launch sites are not indicated in the main Table, but the numbers of launches from each site, with the geographical location of the site, are given in the table below.

\begin{tabular}{|c|c|c|c|c|}
\hline Country & Launch site & Latitude & Longitude & Number of launches \\
\hline \multirow[t]{3}{*}{ USSR } & Tyuratam (Baikonur) & $45.6^{\circ} \mathrm{N}$ & $63.4^{\circ} \mathrm{E}$ & 728 \\
\hline & Kapustin Yar & $48.4^{\circ} \mathrm{N}$ & $45.8^{\circ} \mathrm{E}$ & 82 \\
\hline & Plesetsk & $62.8^{\circ} \mathrm{N}$ & $40.1^{\circ} \mathrm{E}$ & 1112 \\
\hline \multirow[t]{3}{*}{ USA } & Cape Canavera1 (ETR) & $28.5^{\circ} \mathrm{N}$ & $81.0^{\circ} \mathrm{W}$ & 373 \\
\hline & Vandenberg AFB (WTR) & $34.7^{\circ} \mathrm{N}$ & $120.6^{\circ} \mathrm{W}$ & 470 \\
\hline & Wallops Island & $37.9^{\circ} \mathrm{N}$ & $75.4^{\circ} \mathrm{W}$ & 19 \\
\hline France & Hammaguir & $31.0^{\circ} \mathrm{N}$ & $8.0^{\circ} \mathrm{W}$ & 4 \\
\hline USA/Italy & $\begin{array}{l}\text { Indian Ocean Platform } \\
\text { (San Marco) }\end{array}$ & $2.9^{\circ} \mathrm{S}$ & $40.3^{\circ} \mathrm{E}$ & 8 \\
\hline Australia/UK & Woomera & $31.1^{\circ} \mathrm{S}$ & $136.8^{\circ} \mathrm{E}$ & 2 \\
\hline \multirow[t]{2}{*}{ Japan } & Uchinoura (Kagoshima) & $31.2^{\circ} \mathrm{N}$ & $131.1^{\circ} \mathrm{E}$ & 16 \\
\hline & Tanega shima & $30.4^{\circ} \mathrm{N}$ & $131.0^{\circ} \mathrm{E}$ & 15 \\
\hline France/Europe & Kourou & $5.2^{\circ} \mathrm{N}$ & $52.8^{\circ} \mathrm{W}$ & 20 \\
\hline \multirow[t]{2}{*}{ China } & Shuang Cheng-tzu (Jiquan) & $40.6^{\circ} \mathrm{N}$ & $99.8^{\circ} \mathrm{E}$ & 14 \\
\hline & Xichang & $28.1^{\circ} \mathrm{N}$ & $102.3^{\circ} \mathrm{E}$ & 3 \\
\hline India & Sriharikota & $13.9^{\circ} \mathrm{N}$ & $80.4^{\circ} \mathrm{E}$ & 3 \\
\hline
\end{tabular}


xvii

\section{ACKNOWLEDGMENTS}

In compiling the Table, our deepest debt is to the North American Aerospace Defense Command: for more than 25 years NORAD has (via NASA) supplied orbital elements on all satellites to the scientific community. We offer our grateful thanks to NORAD for this service, without which not only the Table but also much scientific work on orbit analysis would have been impracticable. Nearer home it is a pleasure to thank the Kettering Group for supplying exact recovery times for hundreds of Cosmos satellites; and the Commanding Officer and staff of RAF, Fylingdales for their essential assistance in making available orbital elements. We are also most grateful to a number of skilled visual observers who have been able to identify components in multiple launches. At RAE our debts are too numerous to specify individually: we particularly thank those who have for many years accurately filed the data on the 17000 satellites, and the many typists who have not only typed the Table skilfully and accurately but have also cheerfully tackled the far worse problem of making thousands of amendments to the masters. 
xviii

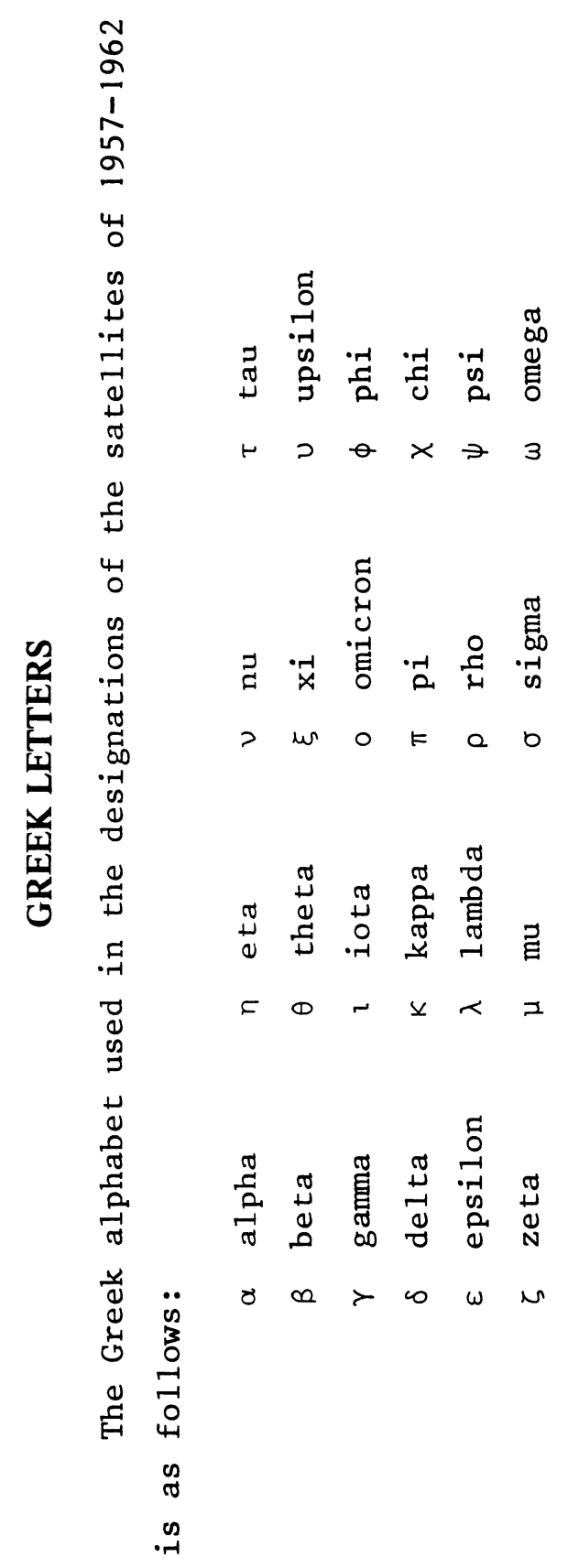

